$$
\begin{aligned}
& \text { Subhan Panji Cipta, Mambang, dan Yuslena Sari. Prediksi Time Series Produksi Crude Palm Oil } \\
& \text { Menggunakan Support Vector Regression Dengan Optimasi Particle Swarm Optimization }
\end{aligned}
$$

\title{
PREDIKSI TIME SERIES PRODUKSI CRUDE PALM OIL MENGGUNAKAN SUPPORT VECTOR REGRESSION DENGAN OPTIMASI PARTICLE SWARM OPTIMIZATION
}

\author{
Subhan Panji Cipta', Mambang ${ }^{2}$, dan Yuslena Sari ${ }^{3}$ \\ 1), 2)Teknologi Informasi, Universitas Sari Mulia \\ ${ }^{3)}$ Program Studi Teknologi Informasi, Fakultas Teknik, Universitas Lambung Mangkurat \\ Email : panji.cipta@gmail.com', mambang@unism.ac.id², yuzlena@ulm.ac.id ${ }^{3}$
}

\begin{abstract}
ABSTRAK
Minyak sawit merupakan minyak yang paling banyak dikonsumsi di dunia. Indonesia sendiri merupakan negara penghasil minyak sawit terbesar di dunia. Selain itu, perkebunan sawit merupakan komoditas devisa utama negara dan juga menyerap jutaan tenaga kerja. Tujuan dari penelitian ini adalah membuat model prediksi minyak sawit mentah (Crude Palm Oil) dengan menggunakan data produksi time series bulanan di Provinsi Kalimantan Selatan yang diambil karena prediksi produksi merupakan acuan untuk mengetahui keuntungan, biaya dan kebijakan bisnis lainnya. Metode yang digunakan dalam penelitian ini adalah Support Vector Regression dengan optimasi Particle Swarm Optimization. Model yang dihasilkan pada penelitian ini adalah parameter C sebesar 628.88548 dan gamma 410.324 pada kernel RBF yang menghasilkan R2 untuk data uji sebesar 0,999 .
\end{abstract}

Kata Kunci : Minyak Sawit Mentah, Regresi Vektor Dukungan, Optimasi Gerombolan Partikel, Deret Waktu.

\section{ABSTRACT}

Palm oil is the most consumed oil in the world. Indonesia itself is the largest palm oil producing country in the world. In addition, oil palm plantations are the country's main foreign exchange commodity and also absorb millions of workers. The purpose of this study is to make a prediction model of crude palm oil (Crude Palm Oil) using monthly time series production data in the province of South Kalimantan, that was taken because the prediction of production is a reference to find out the profits, costs and another business policies. The method that was used in this study is Support Vector Regression with Particle Swarm Optimization optimization. The model that was produced in this study are the parameter C of 628.88548 and gamma of 410.324 in the RBF kernel, which produces R2 for the test data of 0.999 .

\section{Keywords : Crude Palm Oil, Support Vector Regression, Particle Swarm Optimization, Time Series.}

\section{PENDAHULUAN}

Indonesia merupakan negara agraris dimana sektor pertanian menjadi andalan dalam pembangunan nasional. Dimasa lalu bidang pertanian menjadi tolak ukur ekonomi Indonesia melalui peranannya dalam pemasukan Produk Domestik Bruto (PDB), penyerapan tenaga kerja, penghasil ekspor dan lain-lain. Hal itulah yang membuat sebagian masyarakat masih mempertahankan kegiatan pertanian walaupun Indonesia telah menjadi negara industri (Tim Riset PASPI, 2017). Salah satunya kelapa sawit, dimana kelapa sawit menjadi komoditas utama penghasil devisa negara yang cukup besar dengan luas area perkebunan $34,18 \%$ dari luas perkebunan kelapa sawit dunia selain itu kelapa sawit juga berkontribusi dalam peningkatan taraf hidup masyarakat Indonesia melalui penyediaan lapangan pekerjaan (Wirahma, Seto and Athoillah, 20l4). Minyak nabati merupakan salah satu produk yang di hasilkan dari perkebunan kelapa sawit. Sejak tahun 1960-an konsumsi minyak beralih ke minyak nabati, dimana sebelumnya konsumsi minyak dan lemak didominasi oleh minyak hewani. Minyak nabati utama yang menguasai pasar global yaitu minyak kelapa sawit, minyak kedelai, minyak bunga matahari dan minyak rapeseed. Dilihat dari data oil world pada tahun 2017 minyak sawit merajai pasar global yakni 39\% dan diikuti minyak kedelai sebesar $33 \%$, sedangkan di tempat ketiga dihuni minyak rapeseed atau minyak kanola sebesar 17\% dan minyak bunga matahari berada di nomor terakhir dengan 10\% (Wirahma, Seto and Athoillah, 20/4). Peningkatan permintaan produk olahan kelapa sawit sejalan dengan upaya perusahaan untuk menambah produksi, selain itu perusahaan juga berusaha untuk menambah tingkat efisiensi pengolahan, untuk menjaga harga produk-produk kelapa sawit tetap bisa bersaing. Beberapa faktor yang mendasari perumusan kebijakan efisiensi ialah gambaran penerimaan. Sedangkan gambaran penerimaan itu sendiri adalah turunan dari prediksi produksi dan akan menjadi asas prediksi keuntaungan serta biaya dan kebijakan bisnis lainnya. Prediksi produksi berpengaruh terhadap kelangsungan kegiatan dan waktu produksi perusahaan, 
seperti banyaknya pekerja panen, jumlah alat panen, pemupukan serta keperluan kendaraan untuk mengangkut hasil. Oleh sebab itu, mendapatkan prediksi produksi yang tepat penting dilakuka (Santosa, Sulistyo and Dharmawan, 20I I).

Dalam penelitian yang dilakukan oleh Kenned were dkk. yaitu A Comparative Assessment Of Support Vector Regression, Artificial Neural Networks, And Random Forests For Predicting And Mapping Soil Organic Carbon Stocks Across An Afromontane Landscapedan penelitian lain yang dilakukan oleh mustakim dkk. yang berjudul Performance Comparison Between Support Vector Regression And Artificial Neural Network For Prediction of Oil Palm Productionkeduanya menyimpulkan bahwa metode SVR lebih baik dari Artificial Neural Networkdan Random Forest (Smola, Sch and Schölkopf, 2004; Mustakim, Buono and Hermadi, 2016). Dan penelitian lain yang juga dilakukan oleh Mustakim dkk. yaitu Support Vector Regression Untuk Prediksi Produktivitas Kelapa Sawit Di Provinsi Riau menunjukkan bahwa akurasi yang dihasilkan dari metode SVR mencapai 95\% dengan error 6\% pada kernel Radial Basic Function (RBF) (Mustakim, Buono and Hermadi, 20I5).

Berdasarkan penelitian tersebut, dan melihat tingginya tingkat akurasi pada prediksi, maka pada penelitian ini akan menggunakan metode Support Vector Regressiondan akan di optimasi menggunakan Particle Swarm Optimization untuk memprediksi produktifitas produksi Crude Palm Oil di Provinsi Kalimantan Selatan.

\section{METODE PENELITIAN}

\section{I Bahan dan Alat Penelitian}

Bahan yang digunakan dalam penelitian ini adalah data bulanan produki crude palm oil Provinsi Kalimantan Selatan. Untuk Alat penelitian yang akan digunakan adalah sebuah PC (Personal Computer) untuk mengimplementasikan sistem model prediksi. Adapun untuk perangkat lunak yang digunakan adalah sebagai berikut :

I. Microsoft Windows 7 Ultimate sebagai Sistem Operasi.

2. Mathlab R2017b sebagai bahasa pemrograman.

Pada penelitian ini, bahasa pemrograman Mathlab yang digunakan adalah versi Mathlab R20I7b.

\subsection{Perancangan Model}

Perancangan model yang ada merupakan suatu gambaran dari model yang nantinya dibuat sesuai kebutuhan awal berdasarkan analisis data yang telah dilakukan sebelumnya.
Gambaran dari rancangan model yang akan dibuat dapat dilihat melalui gambar I berikut.

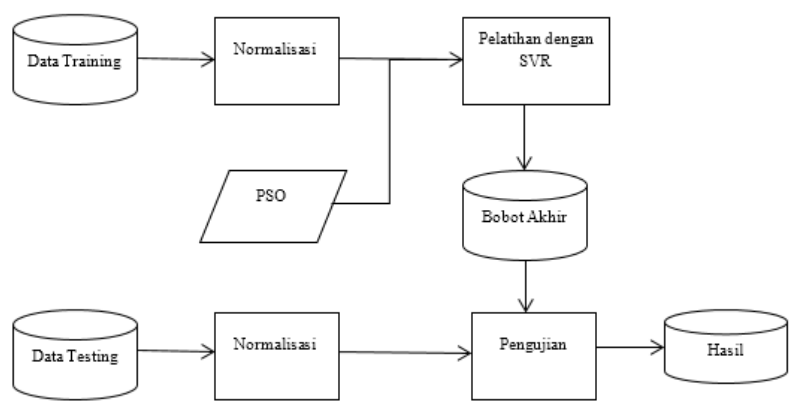

2.3 Perancangan Sistem

Perancangan sistem dibuat berdasarkan berdasarkan model yang telah diusulkan sebelumnya. Proses perancangan sistem ini merupakan gambaran aplikasi yang akan berjalan setelah dilakukan tahapan-tahapan sebelumnya. Perancangan Sistem dapat dilihat pada diagram alir gambar 2 berikut.

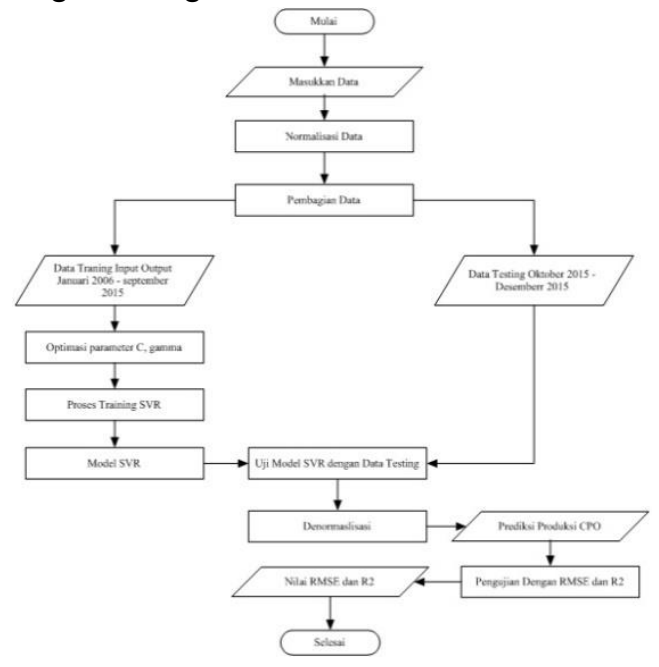

Gambar. 2. Perancangan Sistem

II. HASIL DAN PEMBAHASAN

III.

3.I Hasil Pengolahan Data

Data yang akan di gunakan dalam penelitian ini, seperti yang telah dijelaskan dalam bab-bab sebelumnya adalah berupa data produksi crude palm oil di kalimantan selatan. Data tersebut di peroleh dari e-book yang dikeluarkan oleh Badan Pusat Statistik Nasional. Jumlah data yang terkumpul sejumlah 120 data yang didapatkan dari tahun 2006 sampai tahun 2015. Kemudian data tersebut diolah sesuai dari kebutuhan dalam penelitian ini, yakni data produksi crude palm oil wilayah Provinsi Kalimantan Selatan. Selanjutnya data tersebut 
Subhan Panji Cipta, Mambang, dan Yuslena Sari. Prediksi Time Series Produksi Crude Palm Oil 2021
Menggunakan Support Vector Regression Dengan Optimasi Particle Swarm Optimization

dikumpulkan dalam file excel untuk di gunakan menjadi data input dan output.

\subsection{Pembahasan}

Berdasarkan percobaan yang telah dilakukan dengan pembagian data training dan data testing yang berbedabeda serta perbandingan data input dan output yang berbeda-beda dengan rentang nilai parameter $C$ yaitu $2^{-10}$ sampai dengan $2^{10}$ dan rentang nilai parameter gamma yaitu $10^{-9}$ sampai dengan $10^{3}$ maka dihasilkan model dengan tingkat akurasi yang berbeda-beda pula dengan rincian sebagai berikut:

Tabel I

Hasil Prediksi dengan pembagian Data 70:30

\begin{tabular}{rlllll}
\hline $\begin{array}{c}\text { Input: } \\
\text { output }\end{array}$ & $\mathrm{C}$ & $\begin{array}{c}\text { Parameter } \\
\text { Gamma }\end{array}$ & $\begin{array}{c}\text { RMSE } \\
\text { Uji }\end{array}$ & R2 Uji \\
\hline I:I & 439.4593 & 18.9262 & 1.100 & 0.570 \\
2:1 & 433.4593 & 21.9262 & 0.866 & 0.495 \\
3:1 & 425.4593 & 22.9262 & 0.849 & 0.448 \\
4:I & 836 & 75.9262 & 0.616 & 0.294 \\
5:1 & 924 & 95.9262 & 0.624 & 0.354 \\
6:1 & 638.4593 & 47.9262 & 0.757 & 0.434 \\
$7: 1$ & 1024 & 127.9262 & 0.910 & 0.211 \\
8:1 & 779 & 120.9262 & 1.037 & 0.179 \\
9:1 & 903 & 146.9262 & 0.983 & 0.165 \\
10:1 & 1024 & 160.9262 & 1.004 & 0.165 \\
\hline
\end{tabular}

Seperti terlihat pada tabel I pada percobaan ini menggunakan data $70 \%$ data training dan $30 \%$ data testing menggunakan kernel RBF. Hasil dengan error terkecil didapat pada percoaan pertama dengan perbandingan data input dan data output yaitu I:I. Pada percobaan tersebut menghasilkan parameter terbaik yaitu dengna parameter C 1024 dengan gamma 135,9262, sedangkan pada percobaan berikutnya dengan perbandingan 2:I sampai perbandingan 10:1 nilai error cenderung semakin membesar.

Percobaan selanjutnya dilakukan dengan menggunakan data yang perbandingan antara data training dan data testingnya yaitu 80:20.

Tabel 2

Hasil Prediksi dengan Pembagian Data 80:30

\begin{tabular}{lllll}
\hline $\begin{array}{l}\text { Input: } \\
\text { output }\end{array}$ & $\begin{array}{l}\text { Parameter } \\
\text { C }\end{array}$ & Gamma & RMSE Uji & $R^{2} U j i$ \\
\hline I:I & 1024 & 135.9262 & 0.443 & 0.510 \\
2:I & 836 & 146.8273 & 0.472 & 0.381 \\
3:I & 1021 & 180.3224 & 0.464 & 0.345 \\
4:I & 996.8791 & 190.6455 & 0.415 & 0.262 \\
5:I & 1024 & 206 & 0.372 & 0.210 \\
6:I & 1024 & 204.6455 & 0.394 & 0.233 \\
7:I & 1024 & 204.6455 & 0.612 & 0.278 \\
8:I & 985 & 185.3224 & 0.733 & 0.263 \\
9:I & 996.8791 & 190.6455 & 0.743 & 0.310 \\
I0:I & 1024 & 233.9262 & 0.661 & 0.363 \\
\hline
\end{tabular}

Pada tabel 2, percobaan ini kernel yang digunakan yaitu kernel RBF. Hasil yang didapatkan tidak jauh berbeda dengan percobaan sebelumnya, yaitu dengan hasil terbaik diperoleh pada percobaan pertama dengan perbandingan antara data input dan data output I:I menghasilkan RMSE (Root Mean Square Error) 0.510.

Percobaan selanjutnya dilakukan dengan menggunakan data yang perbandingan antara data training dan data testingnya yaitu 90:10. Hasil percobaan dapat dilihat pada tabel 4.6 berikut

Tabel 3

Hasil Prediksi dengan Pembagian Data 70:30

\begin{tabular}{|c|c|c|c|c|}
\hline $\begin{array}{l}\text { Input: } \\
\text { output }\end{array}$ & $\begin{array}{l}\text { Parameter } \\
\text { C }\end{array}$ & Gamma & $\begin{array}{l}\text { RMSE } \\
\text { Uji }\end{array}$ & $R^{2} U_{j}$ \\
\hline$I: I$ & 1024 & 257.9262 & 0.322 & 0.483 \\
\hline $2: 1$ & 1024 & 369 & 0.323 & 0.324 \\
\hline 3:1 & 1024 & 418.3224 & 0.328 & 0.219 \\
\hline $4: 1$ & 795 & $402.142 I$ & 0.317 & 0.165 \\
\hline $5: 1$ & 1024 & 475.3224 & 0.305 & 0.002 \\
\hline $6: 1$ & 1024 & 486 & 0.267 & 0.620 \\
\hline $7: 1$ & 779.0414 & $4|4.142|$ & 0.182 & 0.452 \\
\hline 8:1 & 389.4593 & 289.9262 & 0.152 & 0.915 \\
\hline 9:1 & 808.4708 & 422.2368 & 0.081 & 0.974 \\
\hline $10: 1$ & 628.8548 & 410.3224 & 0.044 & 0.999 \\
\hline
\end{tabular}


Seperti pada percobaan sebelumnya, tabel 3 menunjukkan percobaan menggunakan kernel RBF. Hasil nilai error terkecil untuk prediksi produksi crude palm oil diperoleh pada percoaan ke-10 dengan perbandingan anata data input dan data ouputnya yaitu 10:1 menghasilkan nilai RMSE uji sebesar 0,044 dan $R^{2}$ 0,999.

Dari semua percobaan yang telah dilakukan diperoleh model terbaik, yaitu pada percobaan dengan menggunakan perbandingan antara data latih dan data uji 90:10 dengan 10 data input dan I data output diperoleh pada parameter $C$ sebesar 628.8548 dan gamma sebesar 410.3224. adapun diagram perbandingan antara data aktual dan data prediksi yang diperoleh dari data uji dapat dilihat pada diagram gambar 3 berikut.

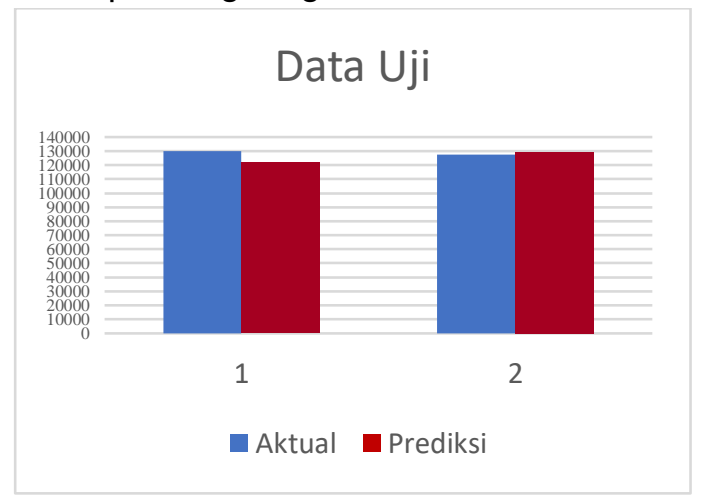

Gambar. 3. Diagram perbandingan data aktual uji dengan prediksi uji

Seperti yang terlihat pada gambar diatas, hasil prediksi terhadap data ujinya memiliki selisih yang kecil. Data aktual uji pada bulan pertama adalah 129.818 sementara data prediksi ujinya $12181 \mathrm{I}$. Data aktual uji pada bulan kedua yaitu 127.412 sementara data prediksi ujinya adalah 129.618

\section{DAFTAR PUSTAKA}

[1]. Mustakim, Buono, A. and Hermadi, I. (20I5) 'Support Vector Regression Untuk Prediksi Produktivitas Kelapa Sawit Di Provinsi Riau', Jurnal Sains, Teknologi dan Industri, I2(2), pp. I79-I88.

[2]. Mustakim, Buono, A. and Hermadi, I. (2016) 'Performance Comparison Between Support Vector Regression And Artificial Neural Network For Prediction Of Oil Palm Production Mustakiml', Jurnal Ilmu Komputer dan Informasi (Journal of Computer Science and Information), 9( I), Pp. I-8. doi: 10.7537/marsrsj0807/6.02.Keywords.

[3]. Santosa, E., Sulistyo, H. and Dharmawan, I. (20I I) 'Peramalan produksi kelapa sawit menggunakan peubah agroekologi di Kalimantan Selatan', J. Agron. Indonesia, 39(3), pp. 193-199.
[4]. Smola, A. J., Sch, B. and Schölkopf, B. (2004) 'A Tutorial on Support Vector Regression', Statistics and Computing, 14(3), pp. 199-222. doi: 10.1023/B:STCO.0000035301.49549.88.

[5]. Tim Riset PASPI (2017) 'Kebijakan nasional dalam industri sawit menuju Indonesia pada urutan 10 besar dunia', Monitor PASPI, III(17), pp. 767-778.

[6]. Wirahma, S., Seto, T. H. and Athoillah, I. (20I4) 'Pemanfaatan Teknologi Modifikasi Cuaca Untuk Perkebunan Kelapa Sawit', Jurnal Sains \& Teknologi Modifikasi Cuaca, I5(I), p. 39. doi: 10.29I22/jstmc.vI5il.2656. 